\title{
Thermal Analysis of Welding on Aluminum Plates
}

\section{Rong-Hua Yeh}

Professor, Department of Marine Engineering, National Taiwan Ocean University, Keelung, Taiwan 20224., RHYeh@mail.ntou.edu.tw

Shih-Pin Liaw

Professor, Department of Mechanical and Marine Engineering, National Taiwan Ocean University, Keelung, Taiwan 20224.

Hong-Bin Yu

Graduate Student, Department of Communication and Guidance Engineering, National Taiwan Ocean University, Keelung, Taiwan 20224.

Follow this and additional works at: https://jmstt.ntou.edu.tw/journal

Part of the Engineering Commons

\section{Recommended Citation}

Yeh, Rong-Hua; Liaw, Shih-Pin; and Yu, Hong-Bin (2003) "Thermal Analysis of Welding on Aluminum Plates," Journal of Marine Science and Technology. Vol. 11: Iss. 4, Article 5.

DOI: $10.51400 / 2709-6998.2292$

Available at: https://jmstt.ntou.edu.tw/journal/vol11/iss4/5

This Research Article is brought to you for free and open access by Journal of Marine Science and Technology. It has been accepted for inclusion in Journal of Marine Science and Technology by an authorized editor of Journal of Marine Science and Technology. 


\section{Thermal Analysis of Welding on Aluminum Plates}

\section{Acknowledgements}

The authors gratefully acknowledge support for this study from the National Science Council, project No. NSC 89-2212-E-019-018. Also, they like to give thanks to China Shipbuilding Corporation to offer facility and help in carrying out the welding experiment in this study. 


\title{
THERMAL ANALYSIS OF WELDING ON ALUMINUM PLATES
}

\author{
Rong-Hua Yeh*, Shih-Pin Liaw**, Hong-Bin Yu***
}

Key words: weld, gas tungsten arc, finite difference, aluminum.

\begin{abstract}
This study investigated the temperature distribution of aluminum plates welded by gas tungsten arc. The heat of fusion, the size and distribution of heat source, the travel speed, the heat conduction in the welding direction and the surface heat loss during welding were considered. A numerical scheme was developed to solve the threedimensional problem. With the help of a mathematical model, the effect of welding parameters such as heat input of the weld, preheating of the workpiece and moving velocity of heat source on weld penetration in moderately thick plates were discussed. The steady-state temperature profiles of the welded plate were solved by finite difference method. In addition, an experiment was conducted to verify the theoretical results. The predicted values from the proposed model compared favorably with the experimental data.
\end{abstract}

\section{INTRODUCTION}

Welding is extensively used in the construction of shipbuilding, aerospace automotive, chemical, electronic, and power generation industries. In fusion welding, parts are joined by the melting and subsequent solidification of adjacent areas of two separate parts. Safety and reliability of the welded joints depend on the weld metal geometry, composition, and structure.

Heat flow during welding is of great interest to welding engineers and metallurgists. It not only controls the size of the fusion, but also affects the properties of the resultant weld. The gas tungsten arc (GTA) welding is a process in which a coalescence of metals is produced by heating them with an arc between a tungsten electrode and the workpiece. A good quality weld is characterized by material composition, joint condition,

Paper Submitted 09/08/03, Accepted 11/05/03. Author for Correspondence: Rong-Hua Yeh.

*Professor, Department of Marine Engineering, National Taiwan Ocean University, Keelung, Taiwan 20224. E-mail: RHYeh@mail.ntou.edu.tw

**Professor, Department of Mechanical and Marine Engineering, National Taiwan Ocean University, Keelung, Taiwan 20224.

***Graduate Student, Department of Communication and Guidance Engineering, National Taiwan Ocean University, Keelung, Taiwan 20224. relative position of the welding arc to the joint and welding parameters such as arc current, arc voltage, and torch travel speed, etc. [2]. Therefore, choosing an appropriate set of welding parameters becomes one of the most important tasks in GTA welding process.

The analytical solution to the steady state, two dimensional heat flow problem of thin-plate welding was first derived by Rosenthal [15]. Due to some unrealistic assumptions, heat flow and solidification in the weld pool can not be predicated, and poor agreement exists between calculated and experimental results in the area immediately adjacent to the weld pool. Solving a transient three-dimensional heat conduction equation with convection boundary conditions at the surfaces of the weldment, Boo and Cho [1] obtained the transient temperature distributions in a finite thickness plate during arc welding. A series of GTA welding experiments for various conditions is performed to verify their solutions. Oreper et al. [11] and Oreper and Szekely [12] formulated a mathematical model on the transient fluid flow and temperature fields in a liquid pool generated by a spatially distributed surface heat flux on an initially solid metal block. In the formulation, allowance was made for electromagnetic, buoyant and surface tension force, and the resultant equations were solved numerically. For GTA welding of pipes, Grill [4] studied heat flow during girth welding by the finite difference method. A heat source was assigned to each grid point in the workpiece, and the solution was obtained by using the alternating direction implicit scheme. Later, Kou and Le [9] investigated the heat flow during the welding of pipes. Both steady state heat flow during seam welding and unsteady state heat flow during girth welding were theoretically calculated and experimentally verified.

Considering arc parameters, radiative and convective heat losses and the temperature dependent thermal properties, Sharir et al. [16] employed the finite difference method to calculate the unsteady heat flow during the fusion welding of thin tantalum sheets. Based on the measured shape of the weld pool, Pavelic et al. [14] calculated the temperature distribution in a thin plate of 
steel using the finite difference method. Neglecting heat conduction in the welding direction, Friedman [3] used the finite element method to calculate the temperature and stress distribution in a thin plate being welded. Kou [6] developed a model to describe the steady state, two-dimensional heat flow during the welding of thin plates. The heat of fusion, the size and distribution of the heat source, the temperature dependence of thermal properties, the heat conduction in the welding direction and the surface heat loss during welding were taken into account.

The coupling of the stress and heat transfer analysis provides a detailed insight into the mechanical response of a system when it is under thermal strain. Assuming one-dimensional stress at the plate normal to the weld line, Tall [17] theoretically studied the residual stress in welded plates. Hibbitt and Marcal [5] and Friedman [3] used a two-dimensional finite element method to investigate the latent effect during the welding process with the simplified assumption that the heat of fusion is released linearly between the liquidus and solidus temperatures of the alloys. Later, Lai et al. [10] presented a general numerical model for simulating three-dimensional thermal stress analysis. The model could be used to predict the transient thermal mechanical response of a weld plate.

The purpose of this work was to investigate the steady state three-dimensional heat flow during the GTA welding of plates. The internal heat source corresponds to the arc heat input moves with constant speed. In addition, the heat of fusion, the size and the distribution of the heat source, and the surface heat loss due to both convection and radiation were taken into account in this heat flow model. The explicit finite difference method with successive over-relaxation technique was employed to solve the three-dimensional steady state heat conduction equation of this welding problem. Finally, a simple experiment was performed to verify the theoretical results.

\section{MATHEMATICAL MODEL}

Figure 1 shows the schematic sketches of plates being butt welded with a moving heat source (tungsten electrode). The origin locates at right below the arc, and the welding direction is identical to the positive $x^{\prime}$-axis. The thickness of the plate is given in $z^{\prime}$-axis and is positive toward the bottom. Besides, the tungsten electrode moves with a constant speed $U$. As a result of the heat input, a molten pool is created under the heat source. Due to the combined effects of the electromagnetic force, the plasma jet force, and the surface tension of the liquid metal, the convection in the molten metal pool appears to be rather complex in arc welding. No attempts were made to simulate the weld pool convection. Rather, the effective thermal conductivity was used to account for the effect of convection on heat flow during welding. For a three-dimensional unsteady state heat transfer in the welded plate without any heat generation, the governing equation can be expressed as

$$
\frac{\partial}{\partial x^{\prime}}\left(k \frac{\partial T}{\partial x^{\prime}}\right)+\frac{\partial}{\partial y^{\prime}}\left(k \frac{\partial T}{\partial y^{\prime}}\right)+\frac{\partial}{\partial z^{\prime}}\left(k \frac{\partial T}{\partial z^{\prime}}\right)=\rho c \frac{\partial T}{\partial t}
$$

In equation (1), the temperature of the welded plate is designated as $T$, while $k, \rho, c$, and $t$ are thermal conductivity, density, specific heat of the workpiece and time respectively.

For brevity, it is assumed that the arc heat input area is far smaller than that of the plate and can be considered as a point heat source. No heat generates from the plate. Except during the initial and final transients of the welding process, the temperature distribution in a workpiece of sufficient length is steady with respect to a coordinate system moving with heat source. Under such conditions the time dependent term in equation (1) vanishes and the process is reduced to a steady state (quasi-stationary state) heat flow problem $[2,3]$. For this reason, a new group of variables is given as

$$
x=x^{\prime}-U t \quad y=y^{\prime} \quad z=z^{\prime}
$$

Substituting equation (2) into equation (1), the governing equation then becomes

$$
\alpha\left(\frac{\partial^{2} T}{\partial x^{2}}+\frac{\partial^{2} T}{\partial y^{2}}+\frac{\partial^{2} T}{\partial z^{2}}\right)+U \frac{\partial T}{\partial x}=0
$$

where $\alpha$, thermal diffusivity of the workpiece, is equal to $k /(\rho c)$. The power input of the heat source $Q$ describes the heat flux from the arc. It equals $\eta E I$, where $\eta$ is efficiency of the arc, $E$ is the arc voltage, and $I$ is the welding current. According to Pavelic et al. [14] the heat flux from the arc can be expressed by

$$
q=\frac{3 Q}{\pi a^{2}} \exp \left(-\frac{3 r^{2}}{a^{2}}\right)
$$

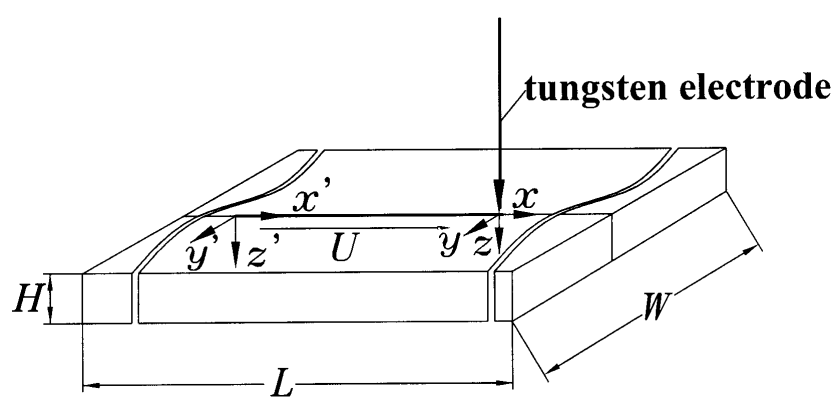

Fig. 1. Schematic sketch of welded plates. 
where $Q, r$, and $a$ are the power input, the distance from the center, and the radius of the heat source, respectively. To complete the mathematical description of the problem, the boundary conditions are specified as follows:

$$
\begin{aligned}
& -k \frac{\partial T}{\partial z}=\frac{3 Q}{\pi a^{2}} \exp \left(-\frac{3 r^{2}}{a^{2}}\right)+h\left(T-T_{a}\right)+\sigma \varepsilon\left(T^{4}-T_{a}^{4}\right) \\
& \text { for } z=0
\end{aligned}
$$

Note that the first term in the right of equation (5) describes the heat input due to the arc, while the second and third terms in the right of equation (5) indicate the heat loss due to convection and radiation. Also, $h$ is the heat transfer coefficient, $T_{a}$ the ambient temperature, $\sigma$ the Stefan-Boltzmann constant, and $\varepsilon$ the total emissivity of the workpiece surface. In addition to the boundary conditions at the top surface, the boundary condition at the bottom surface is given as

$$
-k \frac{\partial T}{\partial z}=h\left(T-T_{a}\right)+\sigma \varepsilon\left(T^{4}-T_{a}^{4}\right) \text { for } z=H
$$

where $H$ is the thickness of the workpiece. At the centerline of the workpiece, the temperature gradient in the transverse direction, i.e., $\partial T / \partial y$, equals zero due to the symmetry requirement. The boundary conditions at the center plane and at side face can be expressed as

$$
\begin{aligned}
& \frac{\partial T}{\partial y}=0 \text { for } y=0 \\
& -k \frac{\partial T}{\partial y}=h\left(T-T_{a}\right)+\sigma \varepsilon\left(T^{4}-T_{a}^{4}\right) \text { for } \mathrm{y}=w / 2
\end{aligned}
$$

where $w$ is width of the welded plate. Far ahead of the heat source $(x \rightarrow-\infty)$, the plate is not affected by the arc input and, therefore its temperature remains unchanged. Far behind the heat source $(x \rightarrow \infty)$, on the other hand, the temperature of the workpiece levels off to a steady value, and $\partial T / \partial x$ approaches zero. In this case, the boundary conditions have the following forms

$$
\begin{aligned}
& T=T_{o} \text { for } x \rightarrow-\infty \\
& \frac{\partial T}{\partial x}=0 \text { for } x \rightarrow \infty
\end{aligned}
$$

In equation (9), $T_{o}$ is the initial temperature of the workpiece.

\section{METHOD OF SOLUTION}

It is reported that the effect of the temperature dependence of the thermal conductivity of solid aluminum on heat flow was very small [8 ] and was, therefore, neglected. The heat of fusion was included in the enthalpy-temperature relationship. Since heat flow is symmetrical with respect to the center vertical plane, only the temperature distribution in one-half of the workpiece was calculated. The arc efficiency $\eta$ of GTA welding may vary according to the welding conditions and materials. For brevity, an arc efficiency of 78 per cent is adopted for all calculations in this study. The governing equation (3), boundary conditions (4) to (10), and the enthalpy-temperature relationship [7] were used to solve the temperature distribution of the workpiece during GTA welding.

The input data for this calculation included the ambient temperature, the initial temperature of the specimen, the size of the specimen and of the elements of the mesh, the initial position of the arc, the thermal properties of the specimen and environment, and the parameters which characterized the arc. The governing equations and the boundary conditions are then transformed into a set of explicit finite difference equations and were solved numerically. In order to verify the calculated results, the selected physical properties were identical to workpieces used in experiment and were given in Table 1 . A $150 \times 60 \times 10$ unevenly spaced grid was used. The successive over-relaxation method with a relaxation parameter of 0.5 was used to assure convergence. It is noted that the source terms in the nonlinear boundary conditions (5), (6), and (8) were linearized [13] during the coding. The iterative procedure of computation was carried out with a personal computer until the following convergence criterion was satisfied.

$$
\left|\frac{T_{\text {new }}-T_{\text {old }}}{T_{\text {old }}}\right|_{\text {maximum }} \leq 0.001
$$

In equation (9), the whole temperatures of the welding plates were examined while executing the calculating program and a relative error of 0.001 for all grid points is selected to be a stopping criterion.

\section{EXPERIMENTS}

The objective of this experiment is to verify the numerical solutions in finite thickness plates of equation (3). In the experiment, 5456 aluminum alloy plates were used as the workpieces to be welded with gas tungsten arc welding machine under various welding conditions. Detailed compositions and weight percentages of 5456 aluminum plates are shown in Table 2. The welded plates are $3.2 \mathrm{~mm}$ thick, $200 \mathrm{~mm}$ wide and 250 $\mathrm{mm}$ long. In addition, the experimental conditions and thermal properties of the welded plates were the same as those used in the numerical calculation and were shown in Table 1. The physical properties used in the calculations are fixed as the values at $300^{\circ} \mathrm{C}$, which is approximately the average value of room temperature and melt- 
Table 1. Thermal properties of the $\mathbf{5 4 5 6}$ aluminum plates and some of the theoretical and experimental conditions

\begin{tabular}{|c|c|c|c|c|c|}
\hline $\begin{array}{l}\text { welding } \\
\text { voltage, } V \\
\text { (V) }\end{array}$ & $\begin{array}{l}\text { welding } \\
\text { current, } \\
I(\mathrm{~A})\end{array}$ & $\begin{array}{l}\text { welding } \\
\text { speed, } \\
U(\mathrm{~mm} / \mathrm{s})\end{array}$ & $\begin{array}{l}\text { Density, } \\
\rho \\
\left(\mathrm{kg} / \mathrm{m}^{3}\right)\end{array}$ & $\begin{array}{c}\text { specific } \\
\text { heat, } c \\
\left(\mathrm{~J} / \mathrm{kg} \bullet{ }^{\circ} \mathrm{C}\right)\end{array}$ & $\begin{array}{c}\text { thermal } \\
\text { conductivity, } \\
k\left(\mathrm{~W} / \mathrm{m} \cdot{ }^{\circ} \mathrm{C}\right)\end{array}$ \\
\hline 10 & $86 \sim 125$ & $3 \sim 7.24$ & 2700 & 1066 & 116 \\
\hline $\begin{array}{c}\operatorname{arc} \\
\text { efficiency, } \\
\eta\end{array}$ & \multicolumn{2}{|c|}{$\begin{array}{c}\text { Stefan-Boltzmann } \\
\text { constant, } \sigma \\
\left(\mathrm{W} / \mathrm{m}^{2} \cdot \mathrm{K}^{4}\right)\end{array}$} & \multicolumn{2}{|c|}{$\begin{array}{l}\text { heat transfer } \\
\text { coefficient, } h \\
\left(\mathrm{~W} / \mathrm{m}^{2} \cdot \mathrm{K}\right)\end{array}$} & $\begin{array}{l}\text { emissivity of } \\
\text { the surface, } \varepsilon\end{array}$ \\
\hline 0.78 & \multicolumn{2}{|c|}{$5.67 \times 10^{-8}$} & \multicolumn{2}{|c|}{10} & 0.82 \\
\hline
\end{tabular}

Table 2. Compositions and weight percentages of 5456 aluminum plates

\begin{tabular}{ccccc}
\hline Composition & $\mathrm{Al}$ & $\mathrm{Mn}$ & $\mathrm{Mg}$ & $\mathrm{Cr}$ \\
\hline Weight $\%$ & 93.9 & 0.8 & 5.1 & 0.12 \\
\hline
\end{tabular}

ing temperature. Also, note that the effective liquid conductivity is about 1.5 times the value of the solid thermal conductivity whereas the specific heat of liquid aluminum is equivalent to that of solid one. The GTA welding parameters were welding voltage: $10 \mathrm{~V}$, welding current: $86 \mathrm{~A}-125 \mathrm{~A}$, travel speed: $3 \mathrm{~mm} / \mathrm{sec}-7.24$ $\mathrm{mm} / \mathrm{sec}$, respectively. Oxide films were polished off the surfaces of the plates before the experiment. The polished surface was then cleansed with acetone just before welding. Furthermore, the workpieces were thermally insulated from the fixtures in order to avoid heat sinks during welding. Argon gas was used for both welding and protecting the underside of the plate. Twelve $\mathrm{K}$-type thermocouples were positioned in the workpieces as shown in Figure 2, six on the top and six on the bottom surfaces of the aluminum plates. All the thermocouples were precalibrated by a quartz thermometer with $0.1^{\circ} \mathrm{C}$ precision, and all of the data signals were collected and converted by a data-acquisition system (a hybrid recorder). The data-acquisition system then transmitted the converted signals through a generalpurpose interface bus to the host computer for further operation. The experiments were repeated under varying process variables such as arc current, travel speed and initial temperature of the welded plates. Detailed experimental procedures can be found from the author's previous investigation [18].

\section{RESULTS AND DISCUSSION}

Figures 3(a), 3(b), 3(c), and 3(d) show the calculated isotherms of the welded plate for $Q=1100 \mathrm{~W}, a=$ $3 \mathrm{~mm}$, and $U=4.23 \mathrm{~mm} / \mathrm{sec}$. The simulation of heat flow was carried out using 5456 aluminum as an example.

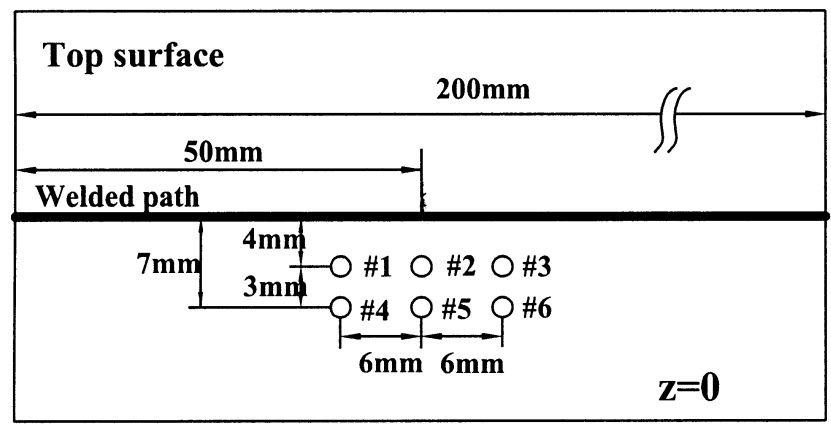

(a)

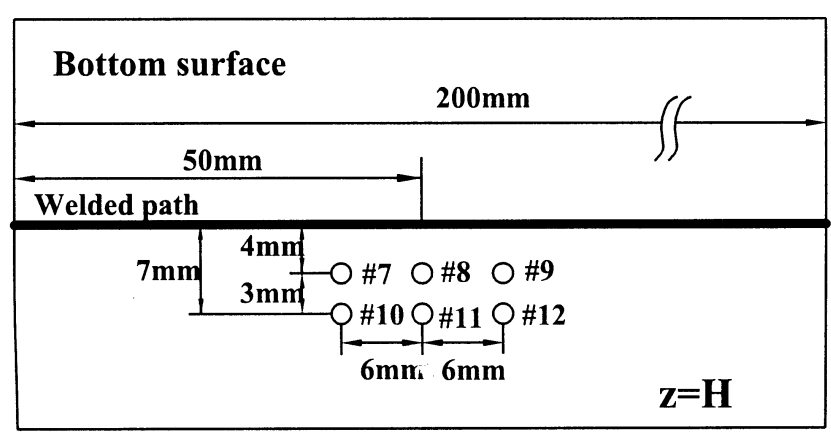

(b)

Fig. 2. The locations of the welded path and thermocouples on the (a) top and (b) bottom surfaces of the welded plate.

The sizes of the welded plates are the same as those used in experiment. Note that Figures 3(a) and 3(b) are the isotherms of the workpiece which are viewed from the positive $x$ and $y$ axes respectively and Figures 3(c) and 3 (d) are the isotherms on the top and bottom surfaces of the workpiece. In these Figures, $T_{L}, 652^{\circ} \mathrm{C}$ and $T_{S}$, $582^{\circ} \mathrm{C}$, are liquidus and solidus temperatures of the aluminum plates used in this study. It can be seen from Figure 3(a) that the variation of temperature is large in the fusion zone. The temperature profiles in the right portion are identical to those in the left due to the symmetric boundary conditions. The difference of temperature between the top and bottom surfaces of the 
welded plate is insignificant at about $5 \mathrm{~mm}$ from the heat source. In Figure 3(b), it is noted that the weld is not symmetrical with respect to the center of the electrode, i.e., the origin. The front of the fusion boundary is about $3.5 \mathrm{~mm}$ ahead of the origin, while the tail is $2.5 \mathrm{~mm}$ behind. This is because heat continued to build up during welding and the areas yet to be welded were preheated. Apparently, the problem is no longer two dimensional but three dimensional, due to the travel of the heat source. Comparing Figure 3(c) with Figure 3 (d), the fusion area of the top surface is larger than that of the bottom whereas no pronounced differences in the calculated isotherms for temperatures lower than solidus temperature, $T_{S}$. Also note that the isotherms in the upper portions are symmetric to the lower portions whereas the fusion boundary in the left portion is smaller than that in the right. This can be easily understood from the observations of isotherms shown in Figures 3 (a) and 3(b). Figures 4(a) and 4(b) display the calculated isotherms and measured data for the top and bottom surfaces of the workpiece and for $V=10 \mathrm{~V}, I=$ $86 \mathrm{~A}$ and $U=3 \mathrm{~mm} / \mathrm{sec}$. The effective radius of the arc is $3 \mathrm{~mm}$ and the arc efficiency is fixed at $78 \%$. It should be emphasized that the heat input is too small to have full penetration in this case. As can be seen in this figure, the agreement between the calculated values and experimental data are in reasonable agreement. The temperatures, points No. 1, 4, 7, and 10, measured behind the tungsten electrode appear a little higher than the calculated results. This is due to the fact that the ambient temperature, especially the regions behind the heat source, rises quickly during the welding process. Consequently, poor heat transfer can be found in the region behind the electrode for smaller temperature

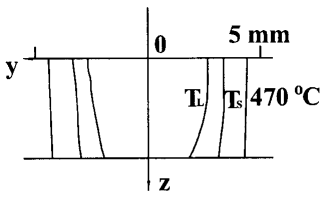

(a)

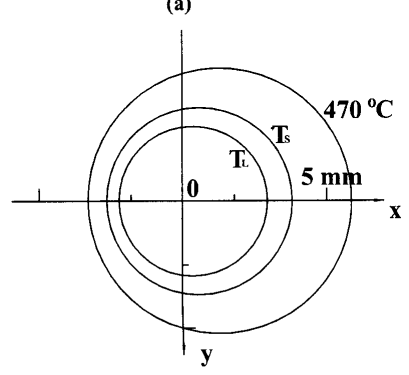

(c)

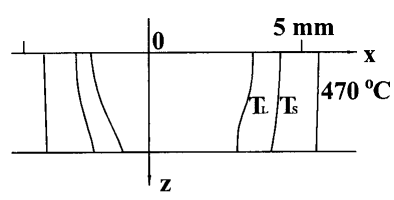

(b)

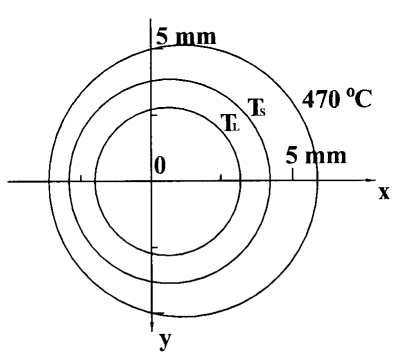

(d)
Fig. 3. The calculated isotherms of the (a) front (b) left (c) top and (d) bottom views of the cross-section area under the moving heat source $(Q=1100 \mathrm{~W}, a=3 \mathrm{~mm}$, and $U=4.23 \mathrm{~mm} / \mathrm{s})$. difference between workpiece and environment, and the measured temperatures appear higher than the predicted ones. This is further demonstrated in Figures 5(a) and 5 (b) by increasing the welding current from 86 A to 125 A and the welding speed from $3 \mathrm{~mm} / \mathrm{sec}$ to $7.24 \mathrm{~mm} / \mathrm{sec}$. The differences between the calculated temperatures and measured data in the rear area of the heat source become smaller for a larger welding speed even at a large power input. This is because the increase in the temperature of the environment is smaller at a larger welding speed. As a result, the reduction of heat dissipation from the welded workpiece is insignificant. On the whole, the agreement between the numerical predictions and experimental data is reasonably good.

Figure 6(a) shows the temperatures of the top surface at a distance of $4 \mathrm{~mm}$ and $7 \mathrm{~mm}$ to the heat source for various welding currents and for $U=3 \mathrm{~mm} /$ sec. As can be seen in this Figure, the temperatures of the workpiece increase with the increase of welding currents. The closer the positions approach the heat

\section{Unit: ${ }^{\circ} \mathbf{C}$}

(a)

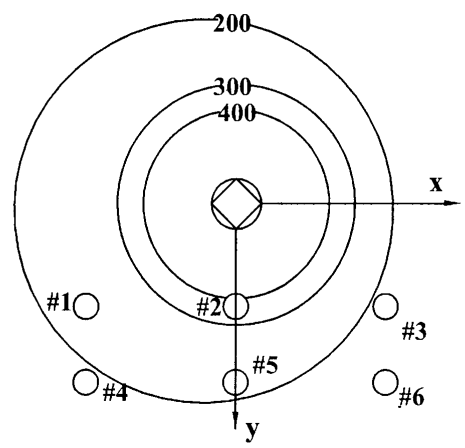

Numerical results Experimental data \#1: 248 "C $\# 2: 403{ }^{\circ} \mathrm{C}$ $\# 3: 205^{\circ} \mathrm{C}$ \#4: $206^{\circ} \mathrm{C}$ \#5: $242{ }^{\circ} \mathrm{C}$ \#6: $184{ }^{\circ} \mathrm{C}$ (b)

\section{$\checkmark$ : Center of moving heat source}

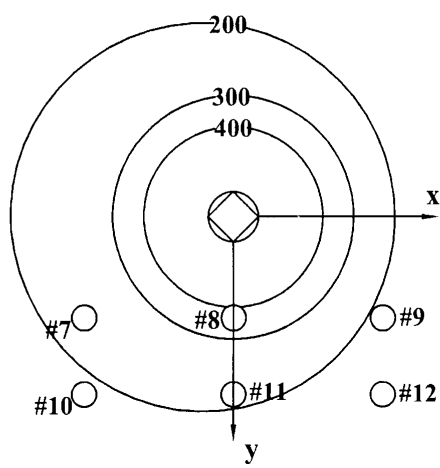

_ Numerical results Experimental data \#7: $203{ }^{\circ} \mathrm{C}$ \#8: $380{ }^{\circ} \mathrm{C}$ \#9: $198{ }^{\circ} \mathrm{C}$ \#10: $193{ }^{\circ} \mathrm{C}$ \#11: $223^{\circ} \mathrm{C}$ \#12: $161^{\circ} \mathrm{C}$

Fig. 4. The calculated isotherms and measured data for the (a) top and (b) bottom surfaces of the workpiece $(Q=670 \mathrm{~W}, a=3 \mathrm{~mm}$, and $U=3 \mathrm{~mm} / \mathrm{s}$ ). 
input, the higher the increasing rates of welded plate temperature are. Also, the measured data appear lower than the theoretical values of this study. The temperatures of the bottom surface at $4 \mathrm{~mm}$ and $7 \mathrm{~mm}$ to the heat source are given in Figure 6(b). Similar trends can be found in this figure but as the welding currents increase, the increasing rates of temperature become smaller. As a whole, the experimental data compare with numerical predictions well.

Figure 7 depicts the temperatures of the top plate surface at $4 \mathrm{~mm}$ and $7 \mathrm{~mm}$ from the weld centerline for various welding speeds. It is shown that the temperatures of the welded plates decrease with welding speeds. This is because the faster the electrode travels, the smaller the preheating effects of the workpiece are. As a consequence, the temperatures of the plates appear lower at a higher travel speed of the heat source. Moreover, the differences between the experimental data and numerical predictions become more pronounced at higher welding speeds. This can be explained from

\section{Unit: ${ }^{\circ} \mathbf{C}$}

(a)

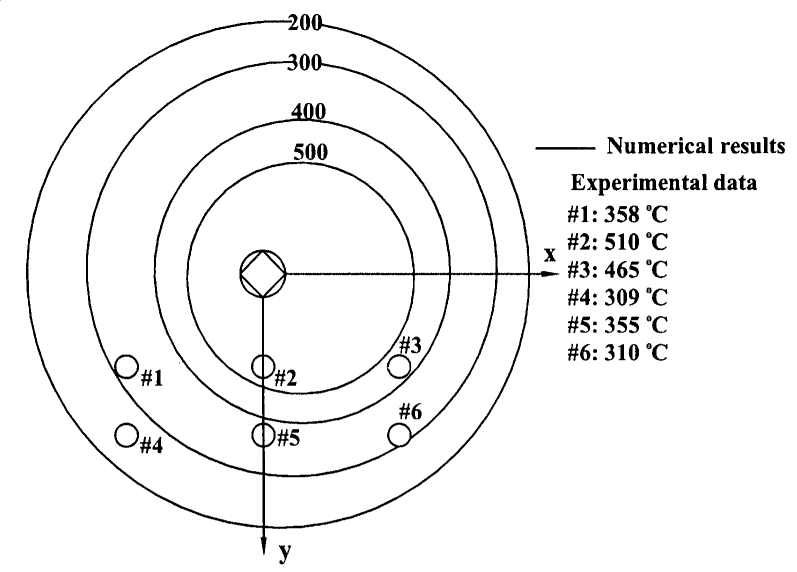

0 : Center of moving heat source

(b)

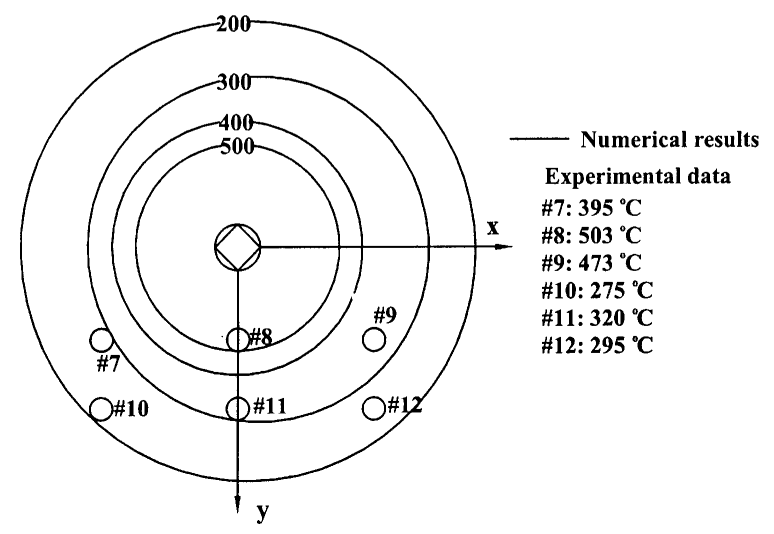

Fig. 5. The calculated isotherms and measured data for the (a) top and (b) bottom surfaces of the workpiece $(Q=975 \mathrm{~W}, a=3 \mathrm{~mm}$, and $U=7.24 \mathrm{~mm} / \mathrm{s}$ ) the fact that the heat transfer coefficients become larger for higher operating speeds, which the proposed model with the assumptions of constant thermal properties fails to predict.

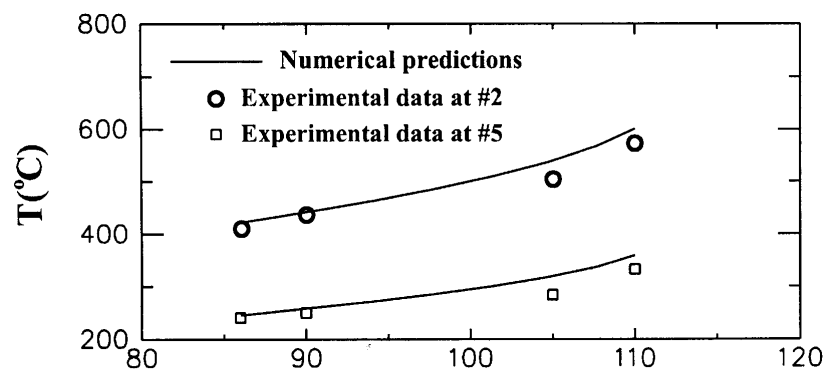

(a)

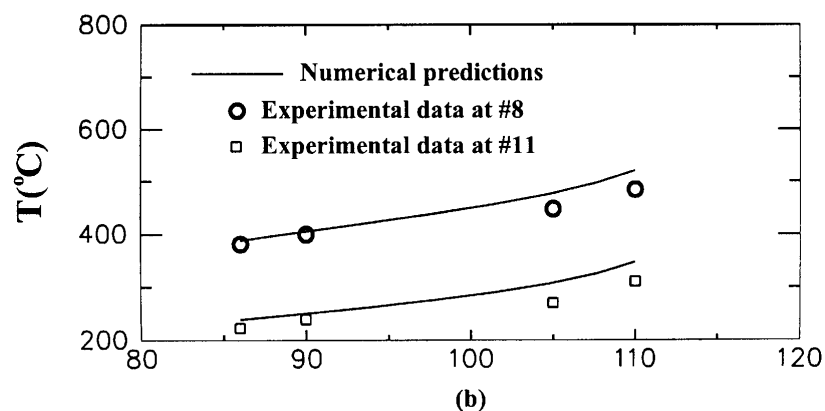

Welding currents (A)

Fig. 6. The temperatures of the (a) top and (b) bottom surfaces at a distance of $4 \mathbf{m m}$ and $7 \mathbf{m m}$ from the weld centerline for various welding currents.

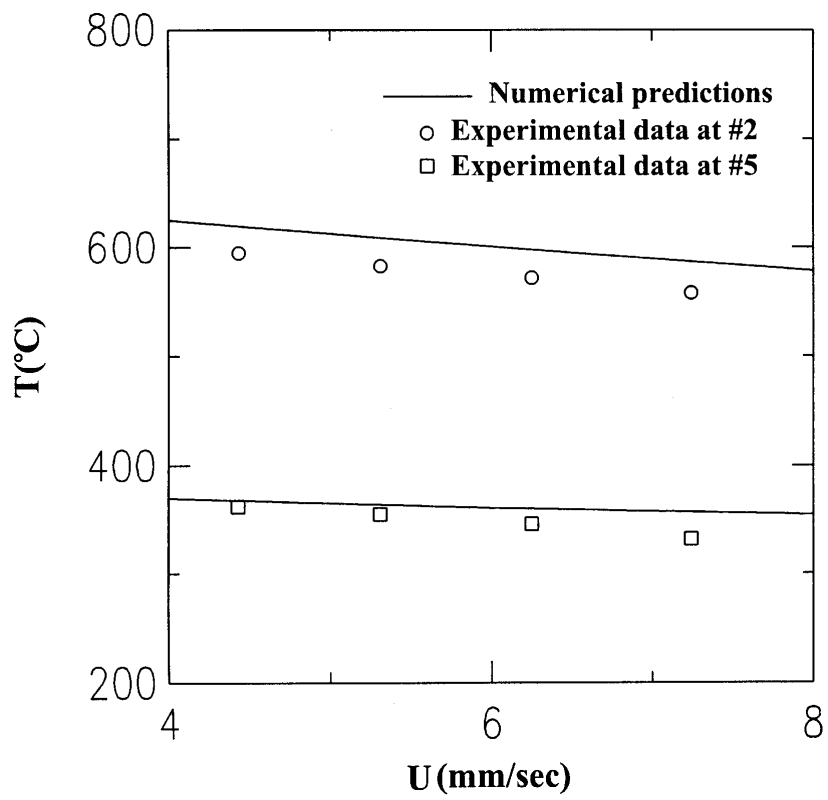

Fig. 7. The temperatures of the top welded plate surface at $4 \mathbf{m m}$ and $7 \mathrm{~mm}$ from the weld centerline for various welding speeds. 


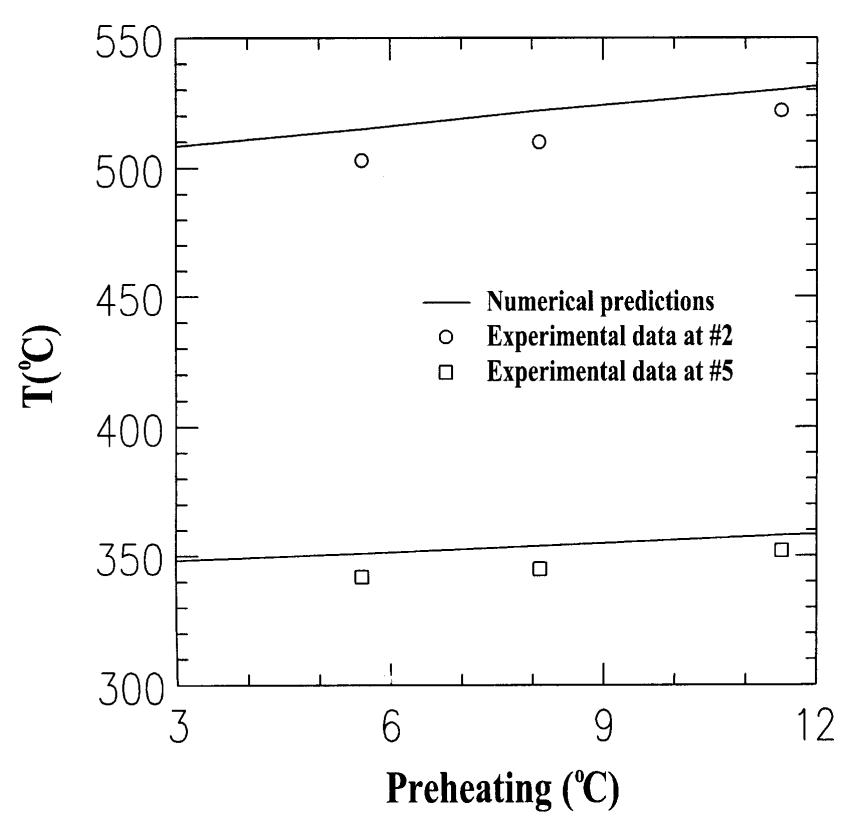

Fig. 8. The effects of preheating for $Q=1 \mathrm{~kW}, \mathrm{U}=3 \mathrm{~mm} / \mathrm{sec}$.

In practice, the constantly rapid heating and cooling of the metal material will result in brittleness, hardness, or crack of the workpiece. Therefore, it is sometimes a better way to preheat the welded plates to prevent the failure of material's mechanical properties. The effects of preheating for $Q=1 \mathrm{~kW}, U=3 \mathrm{~mm} / \mathrm{sec}$ are displayed in Figure 8 . It shows that the both the measured and the calculated temperatures increase as the preheating increases. However, the increase is not so pronounced for a small amount of preheating. In addition, it is observed that the discrepancies between the theoretical solutions and experimental data become smaller at a larger preheating. This is because the temperature variation of the workpiece is smaller for a larger preheating while welding.

\section{CONCLUSIONS}

Numerical and experimental studies of the temperatures on the plates welded by gas tungsten arc were carried out. Major conclusions of this study are summarized as follows:

1. A computer program simulating the three-dimensional steady-state heat conduction in welded plates is developed. To verify the theoretical results, an experiment is conducted under the same welding conditions. The calculated temperatures and measured data especially in the region near the source are compared and good agreement is obtained.

2. The measured as well as the calculated temperatures of the workpiece increase as the preheating increases. However, the increase is not so pronounced for a small amount of preheating.

3. An increase in the heat input results in an increase in the temperatures of the welded plates whereas an increase in the welding speed produces opposite effects.

\section{ACKNOWLEDGEMENT}

The authors gratefully acknowledge support for this study from the National Science Council, project No. NSC 89-2212-E-019-018. Also, they like to give thanks to China Shipbuilding Corporation to offer facility and help in carrying out the welding experiment in this study.

\section{REFERENCES}

1. Boo, K.S. and Cho, H.S., "Transient Temperature Distributions in Arc Welding of Finite Thickness Plates", $J$. Engin. Manufact., Part B, Vol. 204, pp. 175-183 (1990).

2. Dornfeld, D.A., Tomizuka, M., and Langari, G., "Modelling and Adaptive Control of Arc Welding Processes", Measurement and Control for Batch Manufacturing, ASME Winter Annual Meeting, pp. 65-75 (1982).

3. Friedman, E., "Thermo-mechanical Analysis of the Welding Process Using the Finite Element Method", $J$. Pressure Vessel Technol., Vol. 97J, pp. 206-213 (1975).

4. Grill, A., "The Thermal History of a Composite Cylinder Girth Welded by Tig", Int. J. Numerical Methods Engin., Vol. 18, pp. 1031-1037 (1982).

5. Hibbitt, H.D. and Marcal, R.V., "A Numerical ThermoMechanical Model for the Welding and Subsequent Loading of a Fabricated Structures", Computers Struct., Vol. 3, pp. 1145-1174 (1973).

6. Kou, S., "Simulation of heat flow during the welding of thin plates", Metallurgical Trans. A, Vol. 12A, pp. 20252030 (1981).

7. Kou, S., "Welding, Glazing, and Heat Treating-A Dimensional Analysis of Heat Flow", Metallurgical Trans. A, Vol. 13A, pp. 363-371 (1982).

8. Kou, S. and Le, Y., "Three-dimensional Heat Flow and Solidification During the Autogenous GTA Welding of Aluminum Plates", Metallurgical Trans. A, Vol. 14A, pp. 2245-2253 (1983).

9. Kou, S. and Le, Y., "Heat flow during the autogenous GTA welding of pipes", Metallurgical Trans. A, Vol. 15A, pp. 1165-1171 (1984).

10. Lai, C.K.F., Koeing, H.A., and Morral, J.E., “Three Dimensional Thermal Stress Analysis of a Welded Plate by the FEM", Trans. CSME, Vol. 10, pp. 153-165 (1986).

11. Oreper, G.M., Eagar, T.W., and Szekely, J., "Convection in Arc Weld Pools", Welding J., Vol. 68, No. 11, pp. 
307s-312s (1983).

12. Oreper, G.M. and Szekely, J., "Heat- and fluid-flow Phenomena in Weld Pools," J. Fluid Mech., Vol. 147, pp. 53-57 (1984).

13. Patankar, S.V., Numerical Heat Transfer and Fluid Flow, McGraw-Hill, New York (1980).

14. Pavelic, V., Tanbakuchi, O., Uyehara A., and Myers, P. S., "Experimental and Computed Temperature Histories in Gas Tungsten-Arc Welding of Thin Plates," Welding J., Vol. 48, pp. 295s-305s (1969).

15. Rosenthal, D., "The Theory of Moving Source of Heat and Its Application to Metal Treatments," Trans. ASME,
Vol. 68, No. 11, pp. 849-866 (1946).

16. Sharir, Y.A., Grill, A., and Pelleg, J., "Computations of Temperatures in Thin Tantalum Sheet Welding", Metallurgical Trans. B, Vol. 11B, pp. 257-265 (1980).

17. Tall, L., "Residual Stresses in Welded Plates- a Theoretical Study," Welding J. Res. Suppl., Vol. 43, pp. 10s-23s (1964).

18. Yu, H.B., Three-Dimensional Heat Transfer and Temperature Analysis for the Welding Components, M.Sc. Thesis, National Taiwan Ocean University, Keelung (1999). 